\title{
Biceps Brachii Muscle Fatigue During Isometric Contraction: Is Antagonist Muscle Fatigue a Key Factor?
}

\author{
Nicola Lovecchio ${ }^{1}$, Cristian Maiorano ${ }^{2}$, Francesco $\mathrm{Naddeo}^{1}$, Chiarella Sforza $^{*}, 1$ \\ ${ }^{1}$ Laboratorio di Analisi del Movimento (LAM), presso il Dipartimento di Scienze Biomediche per la Salute, Università \\ degli Studi di Milano, Italy \\ ${ }^{2}$ Docente Federale F.I.P.C.F. (Federazione Italiana Pesistica e Cultura Fisica), Italy
}

\begin{abstract}
Purpose: Several studies analyzed muscle activity after pre-fatigue due to co-contraction, but the effects of antagonist contraction on agonist muscle performance are still incompletely known.

The purpose is to determine if a previous workout of an antagonist muscle can affect muscular fatigue appearance during the subsequent agonist muscle performance.

Methods: Surface EMG was used to estimate biceps brachii muscle fatigue during isometric contraction executed after previous contractions of the antagonist muscle. Eight expert male body-builders performed five series of isometric contractions (30 s) alternatively according to the agonist and antagonist protocols.

Results: Within each repetition, for both biceps brachii muscles and experimental protocols, data showed a progressive fatigue, but no continuous quantitative decreasing trend of the median frequency of the spectrum along the five repetitions. Contraction time explained 1-91\% ( $\mathrm{r}^{2}$ values) of the reduction of mean activation frequency along the $30 \mathrm{~s}$ (agonistic protocol); $0.7-92 \%$ for antagonistic protocol. The decrement in median frequency was only partially timerelated. A repeated measures Anova found significant differences between subjects $(\mathrm{p}<0.0001)$, protocols (antagonistic greater than agonistic, $\mathrm{p}=0.03)$, while between sides $(\mathrm{p}=0.93)$ and repetitions $(\mathrm{p}=0.50)$, and for all interactions no significant differences were found.

Conclusion: The present results did not confirm that the antagonistic pre-fatiguing can delay the fatigue appearance during agonistic performance (isometric tasks). Accordingly, the antagonistic protocol does not seem to be functional in improving the upper arm performance from a fatigue point of view, at least in trained subjects.
\end{abstract}

Keywords: Agonistic-antagonistic, bicipes brachii, electromyography, fatigue, isometric contraction, training.

\section{INTRODUCTION}

Fatigue is commonly defined as an exercise-induced decline in performance [1]; it is task dependent and produces impairments either in the activation signal or muscle contractility [2-4]. During an isometric constant and prolonged force effort, even in absence of mechanical manifestations, strong modifications in the intra and extracellular environment occur [5], the increase in intramuscular pressure determines occlusion of blood flow [3], the electric properties of the muscular fiber membrane change [6], and myoelectric manifestations of muscle fatigue become evident $[2,7]$.

During sustained contractions, the amount and rate of change of selected myoelectric signal variables are used to estimate muscular fatigue. Indeed, amplitude and spectral estimators obtained from surface electromyography (sEMG)

*Address correspondence to this author at the Dipartimento di Scienze Biomediche per la Salute, via Mangiagalli 31, I-20133, Milano, Italy;

Tel: +39-02 503 15407; Fax: +39-02503 15387;

E-mail: chiarella.sforza@unimi.it can provide an important assessment of neuromuscular strategies and muscle performance [2, 4, 7-12].

In particular, the recorded signal consists of a weighted summation of the spatial and temporal activity of many Motor Units Action Potentials that propagate along the fibers. Aiming to evaluate muscular fatigue, it is well known how myoelectric manifestations change according to fatigue type, and are proportional to the percentage of maximum voluntary isometric contraction [10].

The relation between the Motor Units Conduction Velocity (MUCV) and the Power Spectrum Density (PSD) is used to study muscle fatigue: a reduction of the MUCV in the time domain corresponds to a scaling of the PSD towards lower values in the frequency domain, due to a decrease of muscle fiber conduction velocity, action potential duration, and motor unit synchronization [8]. The global effect on the sEMG signal is an increase in amplitude and a decrease in mean power frequency [10].

Muscular fatigue affects the athlete training, requiring time to restore muscle conditions, and prolonging the number of sessions and the total time necessary to achieve the desired goals. In parallel with the study of fatigue, 
therefore, other efforts are focused on new methods to reduce training time without decreasing the efficacy of the session [13]. According to this goal, one of the most applied methods, known as 'super-set', consists of immediate contraction of 'back to back' muscles [13, 14] with no recovery time between the two contractions.

Although this kind of training is considered useful for sport actions where both muscles/ muscular groups are active, the effects of pre-fatiguing antagonistic muscles on the activity of reciprocal agonistic muscles are not fully known yet $[13,14]$. Differences about tested muscles, load and type of contraction make the results difficult to compare [13-16]. To date, most of EMG fatigue studies are relative to limb ballistic movement and are focused on concentric/eccentric muscle contraction.

Thus, in the current study, two fatiguing protocols for biceps brachii muscle training (classical and super-set methods) $[17,18]$ were examined to verify muscular fatigue during time. In particular, we wanted to find the best training method to hinder the fatigue effects. SEMG was used to estimate muscular fatigue parameters $[2,7,11,12,19,20]$ to verify which protocol was more efficacious to delay the appearance of fatigue [13], and consequently to hold higher level of strength during time.

\section{MATERIALS AND METHODOLOGY}

\section{Subjects}

Eight expert male body-builders (age, $24 \pm 3.5$ years; weight, $80.5 \pm 8.3 \mathrm{~kg}$, Table 1) volunteered for the study after a detailed explanation of the procedures and possible risks involved. They were selected because they are people able to manage load and usually have an equilibrated level of force (agonistic and antagonistic muscles) in all paired muscles (right $v s$ left). All body builders could interrupt the protocol at any time. Approval was obtained from the local ethics committee; all procedures were not invasive and not potentially harmful.

All subjects were right handed [21] and free from neurological and neuromuscular disorders. They were tested during training regime.

\section{Instrumentation}

sEMG was made using an 8 channels electromyograph and disposable surface electrodes (Freely, De Götzen srl; Legnano, Italy). To detect the sEMG (differential mode) in accord to the SENIAM Protocol [22] disposable, pre-gelled, silver/silver chloride bipolar surface $(21 \pm 1 \mathrm{~mm}$ center-tocenter; diameter $10 \mathrm{~mm}$ ) electrodes (FLAB, Vicchio, Florence, Italy) were placed (Fig. 1) over the longitudinal axis of the biceps brachii muscle [23] parallel to the estimated direction of muscle fibers [24]. A disposable reference electrode was applied to the forehead [25]. Before electrode placement, the skin was cleaned with ethanol. No EMG signal was collected from the triceps brachii muscle because the experimental set up (preacher curl bench, see below and Fig. 1) makes impossible the placement of electrodes on the muscular bellies.

The analog sEMG signal was amplified and digitized (gain 150, peak-to-peak input range $28 \mathrm{mV}$, that is $\pm 14 \mathrm{mV}$, $12 \mathrm{~b}$ resolution, $2230 \mathrm{~Hz}$ A/D sampling frequency, theoretical resolution $16 \mathrm{iV}$ ) using a differential amplifier with a high common mode rejection ratio $(\mathrm{CMRR}=105 \mathrm{~dB}$ in the range $0-60 \mathrm{~Hz}$, input impedance $10 \mathrm{GU})$, and filtered (analogue filtering: lowpass filter with a cut off $580 \mathrm{~Hz}$; digital filtering: range $30-400 \mathrm{~Hz}$; band-stop for common 50 $\mathrm{Hz}$ interference with a notch filter [26], approximate range $47-53 \mathrm{~Hz})$.

The signals were recorded for further analysis. Very low frequency $(<10 \mathrm{~Hz})$ artifacts were limited by the use of the reference electrode (forehead).

To perform the endurance training exercises, a preacher curl bench with $60^{\circ}$ incline plane, a flat bench, a barbell (length $200 \mathrm{~cm}$, diameter $2.8 \mathrm{~cm}$, weight $10 \mathrm{Kg}$ ) and some iron plates of different weight $(1-10 \mathrm{Kg})$ were used.

\section{Experimental Procedure}

The one repetition maximum (1RM) in eccentricconcentric modality was determined for each subject on "preacher curl" (biceps brachii exercise) and on "close grip bench press" (triceps brachii exercise). The two exercises require the use of a barbell and a preacher curl bench (Fig. 1)

Table 1. Anthropometric Characteristics of the Body Builders, and Strength Level Relative to Biceps Brachii (1 RM) and to Triceps Brachii Muscles (1 RM)

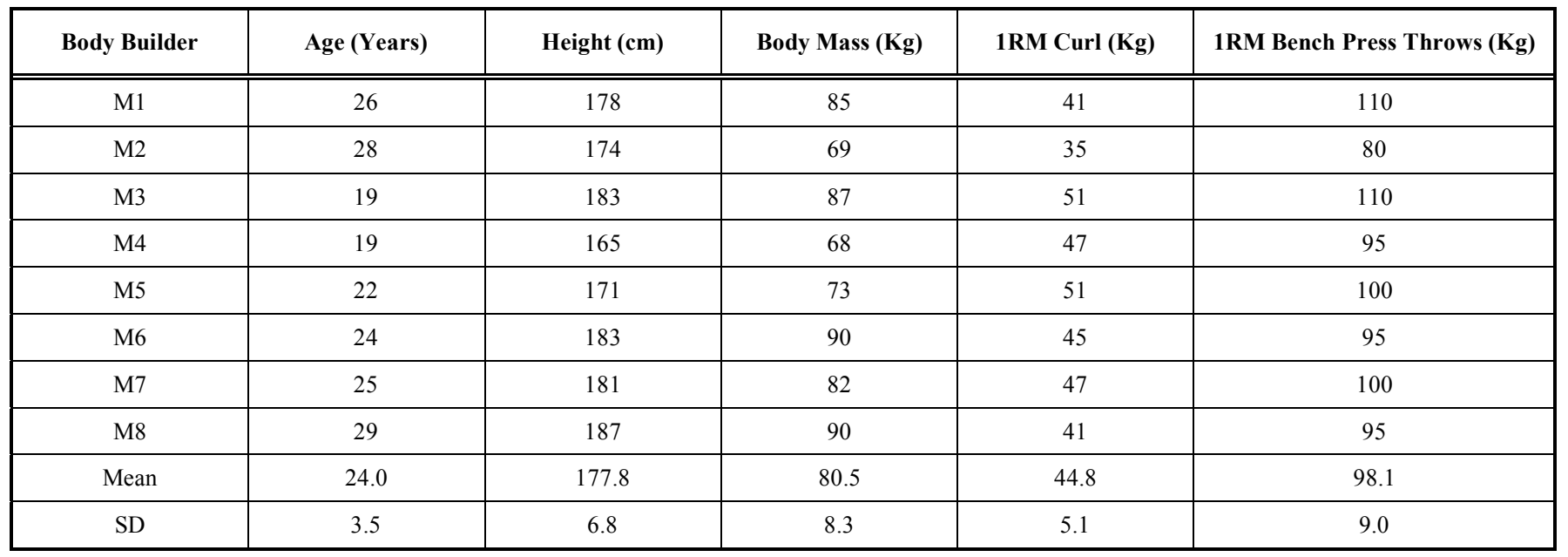




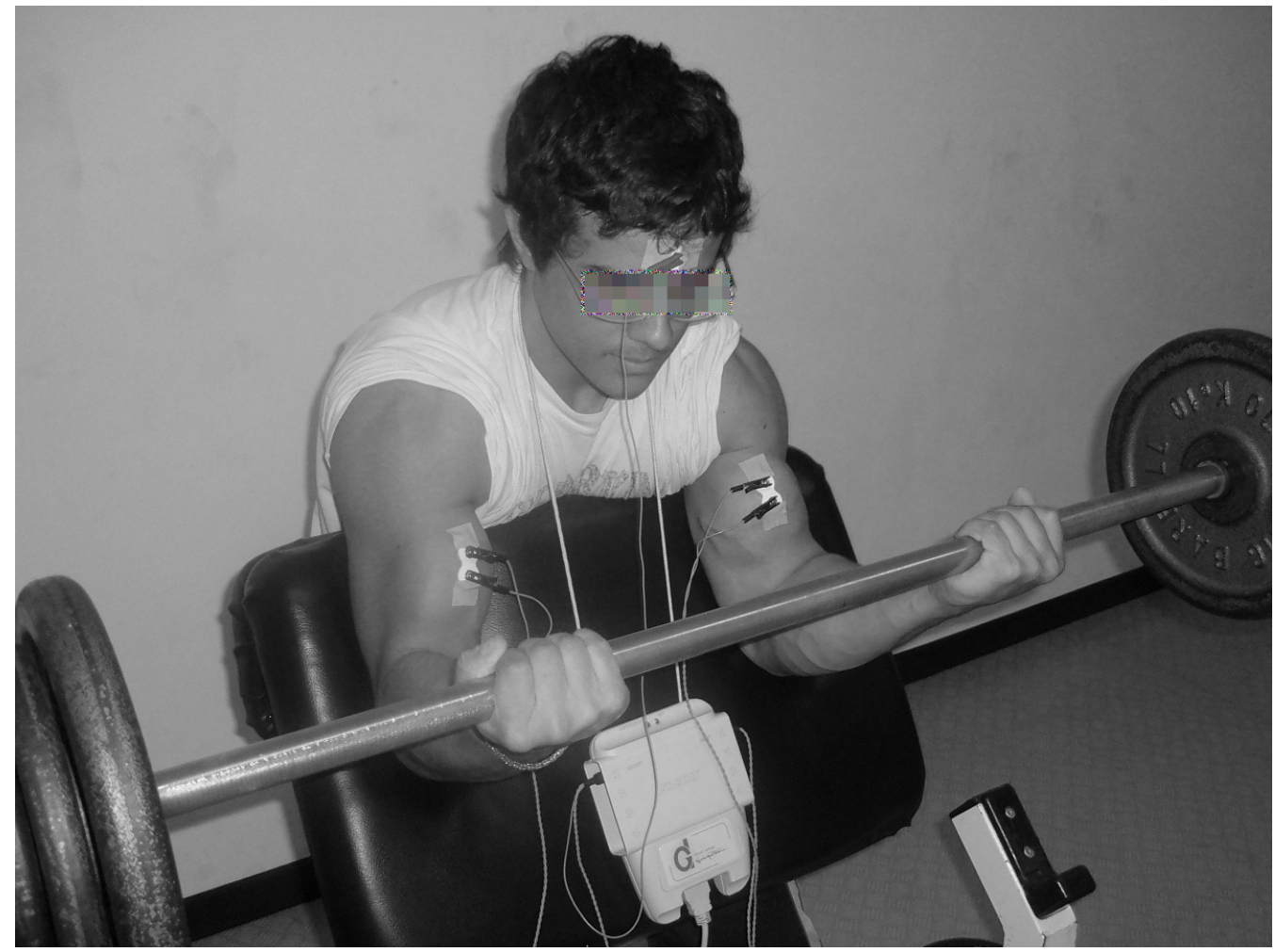

Fig. (1). Upper limbs arrangement and electrode positions during the isometric contraction.

because this set avoids or reduces the intervention of shoulder and trunk muscles. On both exercises the grip width on the barbell was close to shoulder width and the setting. An expert trainer controlled the correct position of the subjects during the performance of all exercises.

Three days after the 1RM test [3, 27], each subject executed the experimental protocol which had been previously randomly assigned to him (4 subjects at the agonist protocol group, 4 subjects at the antagonist protocol group). In the agonist protocol the subjects were asked to perform isometric contractions of the biceps brachii muscles, while in the antagonist protocol (super set method) the biceps brachii contractions were preceded by contractions of the antagonist muscle (triceps brachii).

After a general warm-up composed of a low intensity aerobic activity, the subjects had a specific warm-up (eccentric-concentric contractions) which depended on their specific experimental protocol (Tables $\mathbf{2}$ and 3 ). Subsequently, each subject performed five series of prolonged isometric contractions (simple task used to avoid putative compensation between muscles) [23] while sEMG was recorded from their biceps brachii muscles [28, 29].

Loads and isometric contraction times are reported in Tables $\mathbf{4}$ and 5. The agonist protocol subjects executed an isometric contraction of biceps brachii in the preacher curl exercise, holding up a barbell (loaded according to personal $1 \mathrm{RM})$ with an elbow angle of $90^{\circ}$. The recovery after each contraction was $270 \mathrm{~s}$.

For the subjects of the antagonist group, the isometric contraction in preacher curl exercise were preceded (with a 2 minute interval) by isometric contractions (30 s) of triceps
Table 2. Specific Warm-Up Performed by the Body Builders of the "Agonistic" Group, and Loads Relative to Curl Exercise on Larry Scott Bench

\begin{tabular}{|c|c|c|c|}
\hline Series & Repetitions & \% 1RM & Recovery Length (s) \\
\hline \hline 1 & 5 & 50 & 60 \\
\hline 1 & 4 & 60 & 60 \\
\hline 1 & 3 & 70 & 60 \\
\hline 1 & 2 & 80 & 180 \\
\hline
\end{tabular}

brachii in the close grip bench press with an elbow angle of $140^{\circ}$. The angular elbow positions were checked by an expert technician within a range of $2-3^{\circ}[1]$. In the antagonist protocol, the recovery between preacher curl and close grip bench press was arranged to have the same timing between subsequent biceps brachii contractions as in the agonist protocol. Strong verbal encouragement was given to the subjects during the task.

In both protocols, sEMG potentials were detected during the preacher curl isometric contraction (30 s) according to the endurance time found by Dimitrova et al. (2009) [30] using $80 \%$ of $1 \mathrm{RM}$.

After a week, period in which the body-builders did not perform any upper limb training, the groups were shifted and the tests were repeated at the same time of the first day to avoid the effect of circadian rhythms [3].

Room was kept stable at $24^{\circ} \mathrm{C}$ [6] to avoid reductions in force production and changes in sEMG characteristics [31]. 
Table 3. Specific Warm-Up Performed by the Body Builders of the "Antagonistic" Group and Loads Relative to Curl Exercise on Larry Scott Bench and Bench Press Throws

\begin{tabular}{|c|c|c|c|c|}
\hline Exercise & Series & Repetitions & \% 1RM & Recovery Length (s) \\
\hline \hline Bench press throws & 1 & 5 & 50 & 60 \\
Curl & 1 & 5 & 50 & 60 \\
\hline Bench press throws & 1 & 4 & 60 & 60 \\
Curl & 1 & 4 & 70 & 60 \\
\hline Bench press throws & 1 & 3 & 70 & 60 \\
Curl & 1 & 3 & 80 & 60 \\
Bench press throws & 1 & 2 & 80 & 180 \\
Curl & 1 & 2 & \\
\hline
\end{tabular}

Table 4. Agonistic Fatigue Protocol. Loads and Recovery of Curl Exercise

\begin{tabular}{|c|c|c|c|c|}
\hline $\begin{array}{c}\text { Repetition } \\
\text { Sequence }\end{array}$ & $\begin{array}{c}\text { Contraction } \\
\text { Length (s) }\end{array}$ & $\begin{array}{c}\text { \% } \\
\mathbf{1 R M}\end{array}$ & $\begin{array}{c}\text { Elbow } \\
\text { Angle (Deg) }\end{array}$ & $\begin{array}{c}\text { Recovery } \\
\text { Length (s) }\end{array}$ \\
\hline \hline 1 & 30 & 90 & 90 & 270 \\
\hline 2 & 30 & 90 & 90 & 270 \\
\hline 3 & 30 & 90 & 90 & 270 \\
\hline 4 & 30 & 90 & 90 & 270 \\
\hline 5 & 30 & 90 & 90 & - \\
\hline
\end{tabular}

\section{Data Analysis}

The EMA software (De Götzen srl; Legnano, Italy) was used to analyze the frequency spectrum. In particular, Fast Fourier Transformate (FFT) was assessed in 1-s epochs along the signal [2] and the median frequency of the spectrum was calculated. For each right and left biceps brachii muscle acquisition in every repetition (from 1 to 5) and for both protocols (agonistic and antagonistic), 30 median frequencies $(\mathrm{Hz})$ were thus obtained in each repetition. To assess the timerelated variations in the median frequency associated to the effects of fatigue on muscular contraction [19], separately for each muscle and repetition, all median frequencies were interpolated by linear regression analysis [8] and then slope coefficient $(\mathrm{m})$ was calculated. Thus, 160 regression lines were obtained: $2 \mathrm{~m}$ slope coefficient (right and left side) for each subject $\mathrm{x}$ repetition.

A repeated measures ANOVA was used to determine differences between subjects, experimental protocol, side and repetition. The level of significance was set at 5\%.

\section{RESULTS}

Within each repetition, for both biceps brachii muscles and experimental protocols, data showed a progressive muscular fatigue $(90 \%$ of the $\mathrm{m}$ values were negative, Tables 6 and 7).

Comparing the first repetition with the fifth one during the performance of the antagonistic protocol, all body builders, except M5, M6 and M7, showed an increasing muscular fatigue in both arms (larger absolute values of $\mathrm{m}$ coefficient). In contrast, M5 and M6 did not show fatigue manifestations (the absolute value of $\mathrm{m}$ in the fifth repetition was smaller than the first one), while M7 showed an EMG effect of fatigue only in his right arm.

The same comparison within the agonistic protocol did not show a regular decreasing trend; only M2 and M4 showed EMG indicators of fatigue in both sides.

Table 5. Antagonistic Fatigue Protocol. Loads and Recovery Time of Curl Exercise and Close Grip Bench Press

\begin{tabular}{|c|c|c|c|c|c|}
\hline Exercise & Repetition Sequence & Contraction Length (s) & \% 1RM & Elbow Angle (Deg) & Recovery Length (s) \\
\hline \hline Close grip bench press & 1 & 30 & 90 & 140 & 90 \\
Curl & 1 & 30 & 90 & 120 & 120 \\
\hline Close grip bench press & 2 & 30 & 90 & 90 & 120 \\
Curl & 2 & 30 & 90 & 90 & 120 \\
\hline Close grip bench press & 3 & 30 & 90 & 140 & 120 \\
Curl & 3 & 30 & 90 & 90 & 120 \\
\hline Close grip bench press & 4 & 30 & 90 & 140 & 90 \\
\hline Curl & 4 & 30 & 90 & 120 \\
\hline
\end{tabular}


Table 6. Slope Coefficients (m) of the Time-Related Linear Regressions During the Agonistic Protocol (5 Repetitions $x 2$ Sides), and Mean (SD) Values of the Relevant Regression Coefficients $\left(r^{2}\right)$

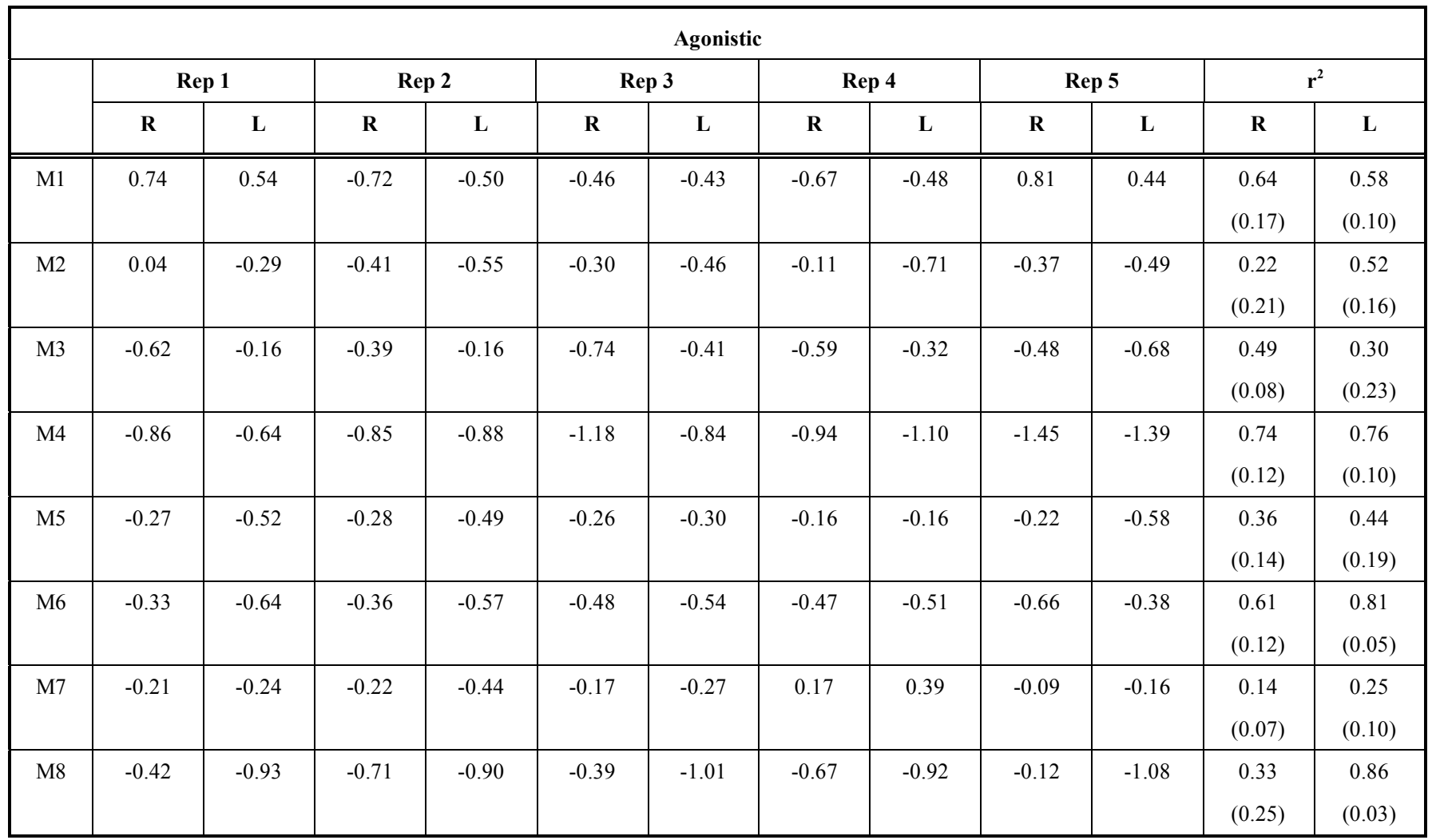

The average $\mathrm{m}$ values did not show a continuous quantitative decreasing trend along the five repetitions (Fig. 2). The difference between close repetitions about the same side $(1-2,2-3,3-4,4-5$, absolute $m$ values $)$ was not negative in all cases (similar trend within side). This manifestation was more frequent in the antagonistic protocol than in the agonistic one.

Contraction time explained from 1 to $91 \%\left(r^{2}\right.$ values, mean values reported in Tables 6 and 7) of the reduction of the median power frequency along the $30 \mathrm{~s}$ (agonistic protocol) and from 0.7 to $92 \%$ for antagonistic protocol. The large variability in $r^{2}$ value indicated that the decrement in median frequency was only partially time-related.

A repeated measures Anova (Table 8) found significant differences between subjects $(\mathrm{p}<0.0001)$, protocols (antagonistic greater than agonistic, $\mathrm{p}=0.03$ ), while between sides $(p=0.93)$, repetitions $(p=0.50)$ and for all interactions no significant differences were found.

\section{DISCUSSION}

sEMG can help trainers and athletes to better their training session and global performance. In the current study, we tried to define the fatiguing appearance due to two different kinds of exercise sequences for the elbow muscles. In the first protocol, all body builders performed isometric contraction of biceps brachii muscles (agonistic) while in the second one the same contraction followed a previous isometric contraction of triceps brachii muscles (antagonistic or super-set).
The EMGs were detected during isometric contraction because it is the best way to record the signal with minimal crosstalk and without electrode movements [7]; the frequency spectrum analysis could explain the fatigue appearance with or without a previous antagonistic contraction.

The median frequency collected in 1-s epochs along the 30 -s signal was significantly different between the two protocols while no differences were found between sides [3]. The lack of side-related differences is in accord with Williams et al. (2002) who monitored a sustained maximum isometric fatiguing task of the elbow flexors, and did not find significant differences in the frequency spectrum between dominant and non-dominant arm.

The lack of significant differences among the five repetitions and the sides can be explained by both the selected task ( $30 \mathrm{sec}$ of contraction may be insufficient to produce fatigue, or recovery time may be too long) or by the good level of training of the current group of body builders that use their right and left side muscles almost symmetrically. Different results may be obtained with less trained subjects, and it may be the topic of a future study. Indeed, Hendrix et al. (2009) [10] during isometric elbow flexor contraction found a significant correlation between force and fatigue threshold when the contraction was maintained for an extended period of time without exhaustion.

The two analyzed protocols produced different decrements (antagonistic greater than agonistic) of the median frequency during the muscular effort (isometric 
Table 7. Slope Coefficients (m) of the Time-Related Linear Regressions During the Antagonistic Protocol (5 Repetitions $x 2$ Sides), and Mean (SD) Values of the Relevant Regression Coefficients $\left(\mathbf{r}^{2}\right)$

\begin{tabular}{|c|c|c|c|c|c|c|c|c|c|c|c|c|}
\hline \multicolumn{13}{|c|}{ Antagonistic } \\
\hline & $\mathbf{R}$ & $\mathbf{L}$ & $\mathbf{R}$ & $\mathbf{L}$ & $\mathbf{R}$ & $\mathbf{L}$ & $\mathbf{R}$ & $\mathbf{L}$ & $\mathbf{R}$ & $\mathbf{L}$ & $\mathbf{R}$ & $\mathbf{L}$ \\
\hline \multirow[t]{2}{*}{ M1 } & -0.53 & -0.39 & -0.44 & -0.45 & -0.58 & -0.57 & -0.52 & -0.64 & -0.82 & -0.46 & 0.58 & 0.52 \\
\hline & & & & & & & & & & & $(0.19)$ & $(0.13)$ \\
\hline M2 & & & & & & & & & & & $(0.11)$ & $(0.28)$ \\
\hline \multirow[t]{2}{*}{ M3 } & -0.43 & -1.38 & -0.82 & -0.59 & -0.54 & -1.56 & -0.82 & -0.94 & -1.60 & -1.50 & 0.31 & 0.62 \\
\hline & & & & & & & & & & & $(0.22)$ & $(0.24)$ \\
\hline M4 & -1.37 & -0.75 & -1.46 & -0.63 & -1.17 & 0.44 & -1.47 & -0.48 & -1.53 & -1.54 & 0.84 & 0.41 \\
\hline \multirow[t]{2}{*}{ M6 } & -0.66 & -0.21 & -0.47 & -0.84 & -0.66 & -0.38 & -0.86 & -0.33 & -0.59 & -0.25 & 0.68 & 0.60 \\
\hline & & & & & & & & & & & $(0.07)$ & $(0.16)$ \\
\hline \multirow[t]{2}{*}{ M7 } & -1.28 & -0.31 & -0.43 & -0.18 & -0.24 & -0.30 & -0.18 & -0.20 & -0.15 & -0.30 & 0.29 & 0.27 \\
\hline & & & & & & & & & & & $(0.32)$ & $(0.11)$ \\
\hline \multirow[t]{2}{*}{ M8 } & -0.81 & -0.70 & -0.65 & -0.94 & -0.94 & -0.79 & -1.03 & -0.95 & -0.94 & -1.26 & 0.74 & 0.83 \\
\hline & & & & & & & & & & & $(0.09)$ & $(0.04)$ \\
\hline
\end{tabular}

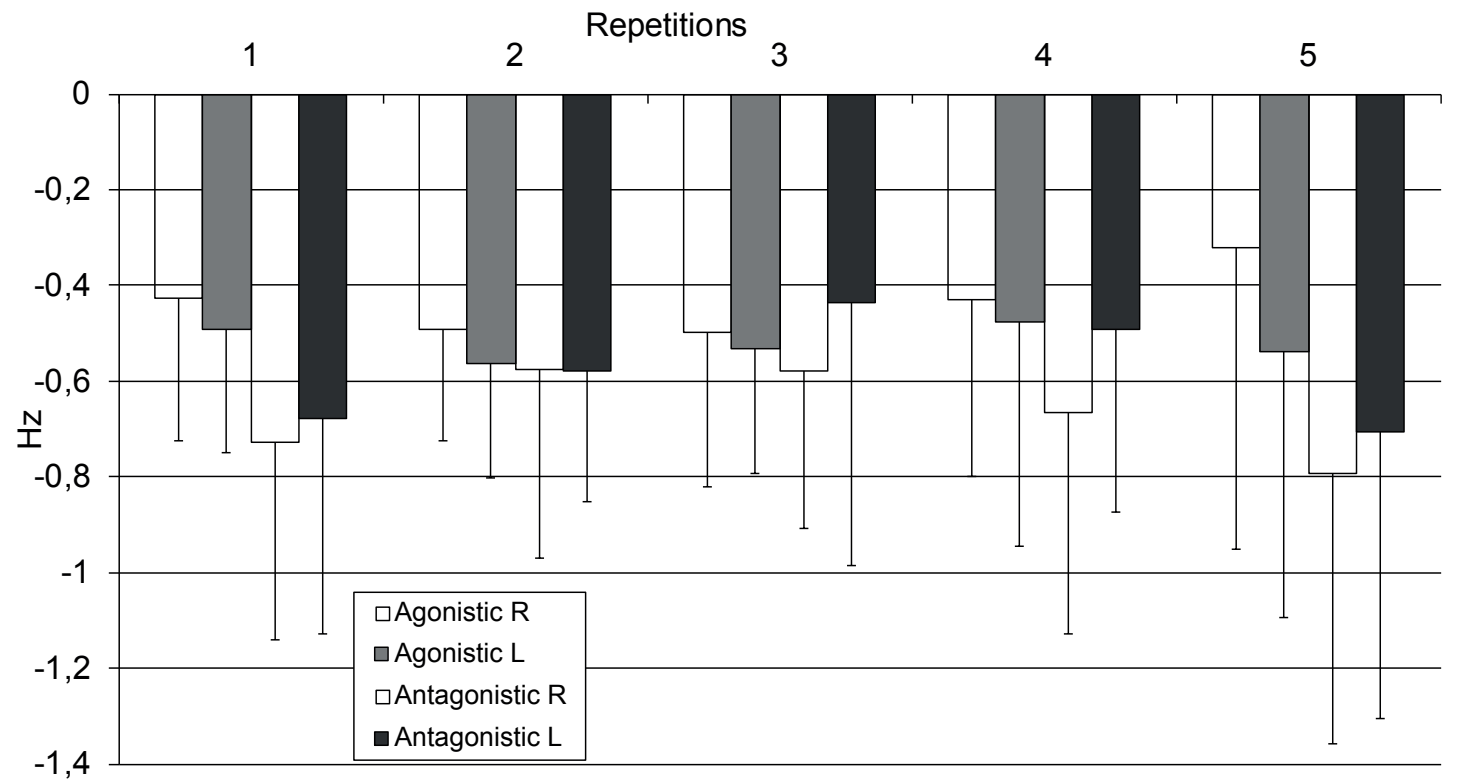

Fig. (2). Mean slope of the time-related linear regressions during the agonistic and antagonistic protocols (5 repetitions $\mathrm{x} 2$ sides for both protocols). Error bars: 1 SD.

contraction). These results disagree with previous data collected during isokinetic tasks of the quadriceps muscles [13]. Those authors found decrements in peak torque and peak power as compared with the non-fatigued state, but no significant differences in quadriceps EMG activity whether muscles were pre-fatigued or not, were detected.
Thus, we do not confirm that the antagonistic prefatiguing could increasing agonistic force generation, at least during low speed actions [13], and during isometric tasks. Indeed, during slow movements (and overall in sustained isometric task) all muscles around the joints change the motor unit control strategies to stabilize the bones with progressive concentric and eccentric contractions [6]. 
Table 8. Repeated Measures ANOVA on the Slope (m) of Median EMG Frequencies During Time

\begin{tabular}{|c|c|c|c|}
\hline Effect & $\begin{array}{c}\text { Degrees of } \\
\text { Freedom }\end{array}$ & F Value & P Value \\
\hline \hline Protocol & 1,152 & 4.77 & 0.03 \\
\hline Side & 1,152 & 0.01 & 0.93 \\
\hline Protocol x side & 1,152 & 2.76 & 0.09 \\
\hline Repetition & 4,152 & 0.83 & 0.50 \\
\hline Protocol x repetition & 4,152 & 1.28 & 0.27 \\
\hline Side x repetition & 4,152 & 0.15 & 0.96 \\
\hline Protocol x side x repetition & 4,152 & 0.26 & 0.90 \\
\hline Subject & 7,152 & 13.73 & $<0.0001$ \\
\hline
\end{tabular}

The present study was made with a reduced number of subjects (but in line with the numbers typical of this kind of investigations) $[2,5,6,19,23,30]$, and even if we tried to standardize their performance using the $1 \mathrm{RM}$, as previously done in literature $[8,23]$, this was not sufficient to reduce inter-subject variability. Additionally, the current values of $\mathrm{r}^{2}$ were very variable [10], and in several occasions the median frequency decrement was not time related, with $\mathrm{r}^{2}$ values close to 0 . The estimation of " $\mathrm{m}$ slopes" values is therefore to be taken with caution.

Decreasing in peak power in slow tasks $\left(60^{\circ} \mathrm{sec}^{-1}\right)$ [13] and a fatiguing manifestation in median frequency during sustained back to back muscle isometric contractions suggest the use of super-set training only during ballistic limb movements [32]. Indeed, Baker \& Newton (2005), using a computerized Plyometric Power System, found an acute effect on power output after antagonistic effort. The alternation of antagonistic and agonistic contractions could reduce the interfering effect of co-contraction, and increase the braking action of antagonists, thus favoring power output action during the performance of fast joint movements [14]. It has to be mentioned that the co-activation of agonist and antagonist muscles plays a key role in joint stability $[11,16]$, and that triceps contraction modulates elbow flexion during this position task (supporting inertial load while maintaining a constant joint angle) thus making the global contraction pattern very complex. Fatigue effects can be different in the agonist and antagonist muscles of a single joint when concentric contractions had been performed [16], but similar with eccentric [11] and isometric (no differences between side) contractions.

Moreover, body builder are able to generate a great level of force that could hide fatigue trend in back-to-back muscles because they are used to managing load in slow movements (at least not ballistic).

\section{CONCLUSION}

In conclusion, the 'antagonist protocol' is not apparently improving the force generation with respect to the fatigue effects, in particular during an isometric task and with trained people.
Further investigations are necessary to fully understand the complex neuromuscular strategy during fatiguing task, the differences between concentric and eccentric muscle contractions $[9,11]$, the role of restricted blood flow during high percentage of $1 \mathrm{RM}$ load task [10, 23, 30], the influence of antagonist muscle activation during agonist muscle isometric contraction, and the fatigue manifestations about antagonist muscle.

Moreover, the variability in spatial change activity, amplitude cancelation [10], variation in the number of active motor units (overall in low load contraction) suggest other investigations and new mathematical model analysis $[6,8]$. A further improvements may be the application of long detecting electrodes to enhance the detection of the EMG signal [30], and the assessment of 'normal-trained' subjects group to evaluate the reliability of the protocol.

\section{CONFLICT OF INTEREST}

The authors confirm that this article content has no conflict of interest.

\section{ACKNOWLEDGEMENTS}

Declared none.

\section{REFERENCES}

[1] Allen TJ, Proske U. Effect of muscle fatigue on the sense of limb position and movement. Exp Brain Res 2006; 170: 30-8.

[2] Merletti R, Knaflitz M, De Luca CJ. Myoelectric manifestations of fatigue in voluntary and electrically elicited contractions. J Appl Phys 1990; 69: 1810-20.

[3] Matkowski B, Place N, Martin A, Lepers R. Neuromuscular fatigue differs following unilateral $v s$ bilateral sustained submaximal contractions. Scand J Med Sci Sports 2011; 21: 268-76.

[4] Molinari F, Knaflitz M, Bonato P, Actis MV. Electrical manifestations of muscle fatigue during concentric and eccentric isokinetic knee flexion-extension movements. IEEE Trans Biomed Eng 2006; 53: 1309-16

[5] Dimitrova NA, Dimitrov GV. Interpretation of EMG changes with fatigue: facts, pitfalls, and fallacies. J Electromyogr Kinesiol 2003; 13: 13-36. Review.

[6] Farina D, Leclerc F, Arendt-Nielsen L, Buttelli O, Madeleine P. The change in spatial distribution of upper trapezius muscle activity is correlated to contraction duration. $\mathrm{J}$ Electromyogr Kinesiol 2008; 18: 16-25

[7] De Luca CJ. The use of surface electromyography in biomechanics J Appl Biomech 1997; 13: 135-63

[8] Bouillard K, Guével A, Hug F. The electromyographic fatigue threshold is not a valid tool to assess muscle function. J Electromyogr Kinesiol 2011; 21: 229-35.

[9] Grabiner MD, Owings TM. EMG differences between concentric and eccentric maximum voluntary contractions are evident prior to movement onset. Exp Brain Res 2002; 145: 505-11.

[10] Hendrix CR, Housh TJ, Johnson GO, et al. A comparison of critical force and electromyographic fatigue threshold for isometric muscle actions of the forearm flexors. Eur J Appl Phys 2009; 105: $333-42$.

[11] Jaskolski A, Andrezejewska R, Marusiak J, Kisisl-Sajewicz K, Jaskolska A. Similar response of agonist and antagonists muscles after eccentric exercise revealed by electromyography and mechanomyography. J Electromyogr Kinesiol 2007; 17: 568-77.

[12] Williams DM, Sharma S, Bilodeau M. Neuromuscular fatigue of elbow flexor muscles of dominant and non-dominant arms in healthy humans. J Electromyogr Kinesiol 2002; 12: 287-94

[13] Maynard J, Ebben WP. The effect of antagonist prefatigue on agonist torque and electromyography. J Strength Cond Res 2003; 17: 469-74.

[14] Baker D, Newton RU. Acute effect on power output of alternating an agonist and antagonist muscle exercise during complex training. J Strength Cond Res 2005; 19: 202-5. 
[15] Grabiner MD. Maximum rate of force development is increased by antagonist conditioning contraction. J Appl Physiol 1994; 77: 80711.

[16] Kellis E, Kouvelioti V. Agonist versus antagonist muscle fatigue effects on thigh muscle activity and vertical ground reaction during drop landing. J Electromyogr Kinesiol 2009; 19: 55-64.

[17] Cometti G. Les methodes modernes de muscolation: donnes theorique. Dijon (Fr): Université de Bourgogne 1997

[18] Poliquin C. Modern Trends in Strength Training: vol. 1. Sets and Reps. $2^{\text {nd }}$ ed. Phoenix (AZ): Charlespoliquin 2001.

[19] Hendrix CR, Housh TJ, Johnson GO, et al. A new EMG frequencybased fatigue threshold test. J Neurosci Methods 2009; 181: 45-51.

[20] Merletti R. Model based interpretation of surface EMG fatigue plots. In: Hermens HJ, Hagg G, Freriks B, Eds. Proceeding of the second general SENIAM Workshop; 1997, Stockolm, Sweden: SENIAM 2, 117. European Application on Surface Electromyography 1997; p. 1007.

[21] Annett M. Subgroup handedness and the probability of nonright preference for foot or eye and of a nonright-handed parent. Percep Motor Skills 2001; 93: 911-4.

[22] Hermens HJ, Freriks B, Disslhorst-Klug C, Rau G. Development of recommendations for SEMG sensors and sensor placement procedures. J Electromyogr Kinesiol 2000; 10: 361-74.

[23] Hug F, Nordez A, Guével A. Can the electromyographic fatigue threshold be determined from superficial elbow flexor muscles during an isometric single-joint task? Eur J Appl Phys 2009; 107: 193-201.

[24] Jensen C, Westgaard RH. Functional subdivision of the upper trapezius muscle during low-level activation. Eur J Appl Physiol Occup Physiol 1997; 76: 335-9.
[25] Ferrario VF, Sforza C, Serrao G, Fragnito N, Grassi G. The influence of different jaw position on the endurance and electromyographic pattern of the biceps brachii muscle in young adults with different occlusal characteristic. J Oral Rehabil 2001; 28: 732-9.

[26] Mandalidis D, Donne B, O’Brien M, Athanasopoulos S. Electromyographic activity of the biceps brachii during maximal voluntary rotation of the abducted shoulder. Open Sports Med J 2008; 2: 69-74.

[27] Siegel JA, Gilders RM, Staron RS, Hagerman FC. Human muscle power output during upper and lower-body exercises. J Strength Cond Res 2002; 16: 173-8.

[28] Merletti R, Roy S. Myoelectric and mechanical manifestation of muscle fatigue in voluntary contractions. J Orthop Sports Phys Ther 1996; 24: 342-53.

[29] Shapiro MP, Prodoehl J, Corcos DM, Gottlieb GL. Muscle activation is different when the same muscle acts as an agonist or an antagonist during voluntary movement. J Mot Behav 2005; 37 : $135-45$.

[30] Dimitrova NA, Arabadzhiev TI, Hogrel JY, Dimitrov GV. Fatigue analysis of interference EMG signals obtained from biceps brachii during isometric voluntary contraction at various force levels. J Electromyogr Kinesiol 2009; 19: 252-8.

[31] Petrofsky J, Laymon M. Muscle temperature and EMG amplitude and frequency during isometric exercise. Aviat Space Environ Med 2005; 76: 1024-30.

[32] Bompa TO, Cornacchia LG. Series Strength Training. In: Bompa TO, Cornacchia LG, Eds. Champaign (IL): Human Kinetics 1998; pp. 30-3.

This is an open access article licensed under the terms of the Creative Commons Attribution Non-Commercial License (http://creativecommons.org/licenses/by-nc/3.0/) which permits unrestricted, non-commercial use, distribution and reproduction in any medium, provided the work is properly cited. 